\title{
Controversy in Managing Coronary Artery Anomaly with Co-Existing Coronary Artery Atherosclerosis in a Young
}

Okoro $\mathbf{S}^{\mathbf{1}}$ and Kardos $\mathbf{A}^{1,2 *}$

${ }^{1}$ Department of Cardiology, Milton Keynes University

Hospital, Milton Keynes, UK

${ }^{2}$ School of Sciences and Medicine, University of

Buckingham, Buckingham, UK

*Corresponding author: Attila Kardos, Department of Cardiology, Milton Keynes University Hospital, 8H Standing Way, Eaglestone, Milton Keynes, MK6 5LD, UK

Received: February 15, 2021; Accepted: March 11, 2021; Published: March 18, 2021

\section{Letter to Editor}

We read the case report by Singh at al. with interest [1]. They present a case of a 34-year-old hypertensive man with symptomatic 3 vessel coronary artery disease on invasive coronary angiography. $\mathrm{He}$ underwent myocardial perfusion scintigraphy with normal perfusion at high workload (12.8 METS and with a double product of 35,720 and had normal left ventricular systolic function on echocardiography. The subsequent CT coronary angiography (CCTA) has described non-occlusive plaques in the left anterior descending coronary artery and proximal Right Coronary Artery (RCA) with an incidental finding of the anomalous RCA originating from the left sinus of Valsalva (LSoV). After this reassuring finding patient underwent invasive coronary angiography that has revealed multivessel disease including 75\% LAD, OM1 and OM2 85\% and RCA 80\% stenosis and coronary artery by-pass graft surgery was recommended.

We would like to raise some points in arguing the appropriateness of this patient's surgical management. ESC and ACC/AHA guidelines recommend optimized medical treatment in patients with low-risk presentation based on typicality of chest pain and the functional test results as in this patient [2]. CCTA is known to have low positive predictive accuracy and tends to overestimate the degree of CAD. It was therefore surprising to see that the degree of the diameter stenosis was underestimated as well as the extent of coronary artery disease in this patient by CCTA was not recognized. One may argue that based on the functional and the non-invasive anatomical test results the best medical practice would have been tight risk factors control and guidelines based optimal medical management. The incidental finding of the CCTA of the Congenital Coronary Artery Anomaly (CCAA) with the RCA originating from the LSoV with inter-arterial course, based on the current clinical evidence, should not have changed management. Indeed, several prospective and retrospective observational studies showed that this type of CCAA is not associated with premature or sudden cardia death in contrast with those when the left coronary artery arises from the right sinus of Valsalva with inter-arterial course [3,4]. Our case-controlled study of 10 patients with the anomalous RCA from the LSoV showed no objective evidence of inducible ischemia on different functional test modalities and showed no event free survival difference compared to age sex and coronary artery disease severity disease matched controls in agreement with other studies $[3,4]$. In addition, since coronary grafts especially venous grafts have limited life expectancy [5], and one would assume that this young patient would need to undergo further revascularization in the future.

We would suggest that best guideline based clinical practice with additional supportive evidence should guide our daily clinical judgement even in cases with complex coronary anatomy to the best interest of our patients [6].

\section{References}

1. Singh S, Civelli VF, Sharma R, Torres B, Sharma O, Anand M, et al. A Case of a High-Risk Coronary Artery Anomaly in a 34-Year Old Caucasian Male. Austin J Clin Cardiolog. 2020; 6: 1067.

2. 2019 ESC Guidelines on the diagnosis and management of chronic coronary syndromes. European Heart Journal. 2020; 41: 407-477.

3. Kalim S and Kardos A. Cardiac CT Angiography Study of the Prevalence and Short-Term Outcome of Older Patients with Anomalous Origin of the Right Coronary Artery from The Left Sinus of Valsalva with Inter-Arterial Course. Cardiology Res Cardiovasc Med. 2019; 6: 147.

4. Cheezum MK, Liberthson RR, Shah NR, Villines TC, O'Gara PT, Landzberg $\mathrm{MJ}$, et al. Anomalous Aortic Origin of a Coronary Artery from the Inappropriate Sinus of Valsalva. J Am Coll Cardiol. 2017; 69: 1592-1608.

5. Antonopoulos AS, Odutayo A, Oikonomou EK, Trivella M, Petrou M, Collins GS, et al. SAFINOUS-CABG (Saphenous Vein Graft Failure-An Outcomes Study in Coronary Artery Bypass Grafting) group. Development of a risk score for early saphenous vein graft failure: An individual patient data metaanalysis. J Thorac Cardiovasc Surg. 2020; 160: 116-127.

6. Warnes CA, Williams RG, Bashore TM, Child JS, Connolly HM, Dearani JA, et al. ACC/AHA 2008 guidelines for the management of adults with congenital heart disease: a report of the American College of Cardiology/American Heart Association Task Force on Practice Guidelines (Writing Committee to Develop Guidelines on the Management of Adults With Congenital Heart Disease). Developed in Collaboration With the American Society of Echocardiography, Heart Rhythm Society, International Society for Adult Congenital Heart Disease, Society for Cardiovascular Angiography and Interventions, and Society of Thoracic Surgeons. J Am Coll Cardiol. 2008; 52: e143-e263. 